\title{
The Effectiveness of Conflict Maps and the V-Shape Teaching Method in Science Conceptual Change among Eighth-Grade Students in Jordan
}

\author{
Ali Khalid Ali Bawaneh (Corresponding author) \\ School of Educational Studies, Universiti Sains Malaysia \\ Minden 11800, Penang, Malaysia \\ E-mail: ali_bawaneh@yahoo.com \\ Ahmad Nurulazam Md Zain \\ School of Educational Studies, Universiti Sains Malaysia \\ Minden 11800, Penang, Malaysia \\ Tel: 60-4-653-2971 Fax: 60-4-657-2907Ｅ-mail: anmz@usm.my \\ Munirah Ghazali \\ School of Educational Studies, Universiti Sains Malaysia \\ Minden 11800, Penang, Malaysia \\ Tel: 60-4-653-2576 Fax: 60-4-657-2907_E-mail: munirah@usm.my
}

\begin{abstract}
The purpose of the present study is to investigate the effectiveness of Conflict Maps and the V-Shape method as teaching methods in bringing about conceptual change in science among primary eighth-grade students in Jordan. A randomly selected sample $(\mathrm{N}=63)$ from the Bani Kenana region North of Jordan was randomly assigned to the two teaching methods (Conflict Maps, $\mathrm{N}=31$; V-Shape, $\mathrm{N}=32$ ). A conceptual multiple-choice test was developed to measure misconceptions regarding electric energy commonly held by eighth-grade students. The data gathered were statistically processed using SPSS software. The results indicated that both methods, Conflict Maps and the V-Shape method, were successful in bringing about conceptual changes in the students. At the same time, the results did not prove either method to be superior in facilitating conceptual shifts regarding electric energy in eighth-grade students. In light of earlier results, this study recommends that curriculum developers take into account teaching methods designed according to conceptual change models and organize training workshops for teachers to learn how to integrate Conflict Maps and the V-Shape method into their teaching. Furthermore, this study recommends that similar studies be conducted with various subjects.
\end{abstract}

Keywords: Conflict maps, V-Shape, Scientific teaching method, Scientific conceptual change, Science teaching.

\section{Introduction}

Scientific advancements in recent years have made integratinging knowledge in detail difficult. In response, science curriculum developers have focused their attention on the very basic principles of science (Abdussalam, 2001), where concepts play a significant role in organizing experiences, recalling knowledge, tracking concepts, linking concepts with their sources, and facilitating concept retrieval (Tayim, Shamout, and Zaitoun, 1984). Al-Aani (1996) argued that learning scientific concepts makes understanding science easier and clearer. Rutherford (1990) emphasized the importance of concepts in scientific understanding and communication, to the degree that concept learning has become a major educational objective at all education levels (Nussbaum, 1989).

The National Science Teachers Association (NSTA, 1982) has identified a scientifically educated person by their ability to use scientific concepts. Similarly, the American Association for the Advancement of Science (AAAS, 1998) recommends focusing on understanding scientific principles and concepts. Along these lines, many educators (Wandersee, Mintez, and Novak, 1994) have become very interested in scientific concept-building processes, which form the core of the science teaching-learning process.

Despite the perceived importance of learning scientific concepts, the related literature typically reports a serious problem faced by students who arrive at school with many concepts that are inconsistent with established scientific knowledge; these are typically referred to as misconceptions or alternative concepts (Lewis \& Linn, 2003; Blosser, 1987; Jaber, 2004). Results from an AAAS study revealed many difficulties in learning scientific concepts, and many high school graduates are unfamiliar with basic scientific concepts (The American Association for the Advancement of Science AAAS, 1989). Similarly, results from the third international study in mathematics and science reported 
indications that students lack a well-established understanding of scientific concepts (National Research Council, NRC, 1996).

Publications by the Jordanian Ministry of Education have revealed that misconceptions are widely held by Jordanian students (Al-Massad, Alabdallah, \& Mdanat, 2002). This result is supported by many studies (Al-Khalil; 1998; Al-Shorman, 2000; Jaber, 2004, Bawaneh, 2004; Baz \& Bawaneh, 2008). Results from the third international study, conducted in 1994-1995 with an international sample of primary eighth-grade students, revealed the prevalence of misconceptions in science and mathematics, where physics was the field in which the majority of the scientific misconceptions were held (Al-Massad et al., 2002).

As misconceptions commonly held by students at various school levels impede their learning of new scientific concepts, it is necessary to change these misconceptions, and thus, many strategies and models have been suggested for this purpose. For example, Al-Khalili, Haidar, \& Younis (1996), Zaitoun (2002), and Tsai (2003) summarized the mechanism by which cognition is built and how cognitive balance is created in one's mind; they drew out this mechanism depending on the cognitive learning theory that emphasizes mental processes taking place in the learner's mind through:

Assimilation: the learner makes changes to the cognitive environment to fit his or her cognitive construct, and Accommodation: the learner changes his or her cognitive construct to fit the environment

Among conceptual change models, Posner's model was the most significant (Posner, Strike, Hewson, Gertzog, 1982) and included four conditions:

Dissatisfaction: refers to a student being dissatisfied with his or her conceptual constructs or with "alternative concepts" that fail to explain the phenomenon encountered

Intelligibility: refers to the clarity of a new concept so that it is principally understandable and believable

Plausibility: refers to the plausibility of a new concept to be linked with previous knowledge networks and employed in resolving problems in which previous concepts fail, and

Fruitfulness: refers to the meaningfulness of a new concept and how effective it is in leading to new fields of inquiry

Clearly, the four conditions proposed by Posner and colleagues are sufficiently elastic to facilitate conceptual change because they did not identify strict roles to be assumed by learners or teachers, nor did they advise any specific teaching method. This, of course, encouraged researchers to use Posner's model in building teaching methods based on the constructivist approach for restructuring concepts, bringing about conceptual change, and assigning specific roles to teachers and learners. For instance, the conceptual conflict approach presumes conflict between two conceptions: one already established in a learner's cognitive structure and a new concept based on mainstream scientific principles. This conflict is resolved when the student realizes that s/he holds a misconception (Shihab, 2004). Another teaching method is the V-Shape method, which outlines the interaction between the conceptual constructs of a discipline and its procedural constructs (Novak \& Gowin, 1995); the events and objects exist in a V-shape intersection where cognitive constructs emerge.

\section{Conflict Maps}

Tsai (2000) proposed a conceptual change strategy, called "Conflict Maps," that is based on Posner's conditions and is represented by a series of critical or conflicting events that relate to an accurate scientific concept. Conflict maps help students search for the balance between the conceptual schemes already held and perceivable facts in the environment. The teacher's role is to create conceptual conflict around the alternative concepts held by students by presenting them with a situation in the environment that contradicts these concepts. Without being given an accurate answer, students are then required to work in small groups on conflict-resolving activities, recording experimental results and constructing possible explanations. The teacher will then present students with new ideas derived from the conflicting event. At this stage, an accurate scientific concept is presented instead that the new concept is offered to students to replace their misconceptions Students will therefore work in small groups to reach accurate explanations of the given scientific concept. The teacher reinforces the accuracy of scientific explanations for students by presenting major concepts related to the specific scientific concept and supporting it with other scientific principles that are more practical and that are associated with the environment.

Figure (1) shows that the use of conflict maps should resolve two conflicts during the process of conceptual change, as supposed by Hashweh (1986); the first is the conflict between the new concept and the older one held by the student as an alternative concept; the second conflict is between the student's alternative concept and the accurate scientific concept (Tsai, 2000; Tsai, 2003).

\subsection{Using conflict maps in conceptual change}

Science teachers and educators can build their own conceptual map, as proposed by Tsai (2000) (see Figure (2)). As shown in Figure (2), Posner's first condition for conceptual change occurs with the Discrepant Event (D.E.) or 
Discrepant Concept (D.C.) in the conflict map. The second condition occurs with the Targeted Science Concept (T.S.C.), whereas the third condition occurs with the scientific concept related to the Critical Event (C.E.). Other ideas related to the scientific concept would correspond to the fourth condition, so that the conflict map will become compatible with the final conceptual constructs at which this process aims (Tsai, 2000). The use of conflict maps clearly enhances conceptual change among students because of the strong coherence between such maps and the conceptual change model proposed by Posner and colleagues (Tsai, 2003).

\section{V-Shape}

Gowin \& Novak (1984) argued that the major motive behind the V-Shape strategy is a willingness to improve and develop experiments and activities that enhance scientific concepts. Furthermore, Gowin \& Novak (1995) demonstrated that the V-Shape method is an instructional tool that outlines the interaction between the conceptual structure in a discipline and its procedural structure, where events and objects intersect in a V-Shape at the center point initiated by the cognitive structure. Gurley, cited in Qilada (2004), considered the V-Shape method as an instrument that identifies the ways in which knowledge is formed as a result of persistent inquiry.

Figure (3), represents the V-Shape method. Novak \& Gowin (1995) explained that the figure consists of two aspects:

- Left side: representing the conceptual side, including concepts, principles, rules, and theories.

- Right side: representing the methodological side, including recordings, transformations, and cognitive and value demands.

Events and objects intersect at the center in a V-Shape, linking both sides.

The overarching main question is placed at the top of the V-Shape, where, through that question, interaction occurs between both sides.

\section{$3.1 \mathrm{~V}$-shape building steps}

The basic units in the V-Shape building process are perceived events and objects. The purpose is to ask the main question and then look for recordings. When the V-Shape is built, a learner should ask him- or herself the following questions:

What objects and events are noticed in light of the main question?

What recordings are produced? What concepts are used to confirm the recordings collected?

What concepts are used in the transformations?

What are the guiding principles, rules, and theories?

How are cognitive demands associated with the preceding principles, rules, recordings, and transformations?

\subsection{V-Shape Strategy Use}

The V-Shape strategy can be used in various fields, including curriculum planning and developing, assessment, the critical review of research studies in different fields, and as an analytical tool for teacher's responses (Esiobu \& Soyibo, 1995; Novak, 2002; Novak \& Gowin, 1984; Zaitoun, 2002; Abdussalam, 2001; Al-Khalili \& Younis, 1996; Khataibeh, 2005). In the present study, the V-Shape strategy will be used as an instructional instrument representing the most recent application of Ausbel's meaningful learning approach. In this context, meaningful learning takes place by linking practical, experimental, theoretical, and cognitive aspects together, in addition to dealing with events and phenomena. The practical aspect will become meaningful when associated with a learner's prior cognitive constructs, thus allowing the instructional content to be treated in a way that renders it educationally useful (Al-Khalili, Haidar, \& Younis, 1996).

Novak \& Gowin (1984) argued that the V-Shape strategy achieves substantial advancement in the teaching-learning process, as the cognitive theory stresses integration between the concepts, principles, and theories used to observe events and the demands of cognitive structures. The cognitive theory provides the learner with a conceptual framework for what has already been learned and works as a cognitive bridge for new knowledge, thus helping the learner to understand the nature and development of knowledge.

Khataibeh (2005) and Zaitoun (2002) indicated that a student's use of the V-Shape in his or her learning makes him or her conscious of what $\mathrm{s} / \mathrm{he}$ does by linking the theoretically based content of concepts, principles, and theorems with practical activities that support more abstract concepts. This, of course, creates an effective interaction between the intellectual (left) and the practical (right) aspects of the V-Shape.

\section{Prior Studies}

A literature review of journals, Arabic and international studies, and the World Wide Web (Internet), as well as various databases, revealed the Arabic and international studies that were focused on conceptual change, particularly in the field of practical education, which uses different teaching strategies, including Conflict Maps and the V-Shape method, in 
comparison with traditional or other methods. To the knowledge of the authors, there has been no study that compares and contrasts Conflict Maps and the V-Shape method as teaching methods for conceptual change, achievement, or any other dependent variable. The following is a brief description of some of the prior studies reviewed.

Barham (1993) used Whitley's conceptual change method in his study, which aimed at identifying the effect of using the constructivist method on bringing conceptual change concerning acids and alkalines among first secondary school students who were following the scientific track in a public school in the Mafraq Governorate, Jordan. The results supported the effectiveness of Whitley's method over traditional methods in bringing about conceptual change.

Cosgrove (1995) sought to identify the significance of using simulation in modifying misconceptions regarding constant electric current. The study found that students who use simulators more often achieved a better scientific understanding of constant electric current, indicating the importance of using simulation to modify misconceptions.

Jaber (2004) aimed at identifying the effect of computer-based instruction in comparison with traditional teaching methods, where both methods were designed based on the conceptual change model. Results indicated no statistically significant difference between these methods in mean conceptual change regarding light among eighth-grade students.

Among studies addressing Conflict Mapping in conceptual change, Tsai (2000) surveyed teachers' views on the use of Conflict Mapping in teaching science. Results revealed that teachers tend to use Conflict Maps, stressing its effectiveness in teaching concepts.

Tsai (2003) explored the effect of using Conflict Maps on changing concepts regarding simple electric circuits. Results from the study supported the effectiveness of Conflict Maps as compared with traditional methods in achieving conceptual change among students.

Baz and Bawaneh (2008) studied the effect of using Conflict Maps on the changing concepts related to electric energy and mechanical waves and other related applications. Results demonstrated that Conflict Maps, when compared with traditional methods, were successful in bringing about conceptual change among students.

The following is a review of some studies that address the V-Shape strategy and its effects on such variables as achievement and conceptual change.

Al-Khraisat (2005) investigated the effect on physics concept acquisition of physics lessons designed in accordance with the fifth learning circle and the V-Shape method in a sample from Amman schools in Jordan. Results indicated no statistically significant difference in physics concept acquisition attributed to either teaching method.

Al-Zoubi (2004) investigated the effect of using the V-Shape method in comparison with traditional method on the acquisition of physics concepts by first-year students in the Faculty of Science at the University of Jordan. Results indicated statistically significant differences among mean scores of the experimental group subjects who were taught using the V-Shape method when compared with the control group, who were taught using traditional lab methods. The results thus favored the experimental group.

Omar (2001) conducted a study that used a proposed strategy for data processing based on a hybrid combination of teaching methods (the V-Shape method, Concept Maps, scientific anecdotes, discussion and dialogue, and instructional activities) intended to develop innovative thinking and higher-order thinking skills among upper primary school-level students. Results revealed a positive effect of using the proposed teaching strategies, including the V-Shape method, on achievement and development of higher-order thinking skills related to scientific concepts.

Passmore (1998) sought to inquire into the effects of using the V-Shape and Concept Mapping methods on learning radiology in a medical lab in the United States. The findings showed that the V-Shape and Concept Mapping methods produced effective learner-lecturer communication styles produced effective communication styles by means of an alternative conceptual adjustment process.

Roth \& Roychon (1993) sought to explore the effect of using the V-Shape and Concept Mapping methods on the conceptual understanding of and attitudes toward science learning among physics students $(\mathrm{N}=27)$ attending a Canadian university. Results demonstrated that the use of concept maps enhanced understanding, lessened difficulties, and produced positive attitudes toward science learning more than did the V-Shape method.

\section{Statement of the Problem}

Educators (Rutherford, 1990; Nussbaum, 1989; Abdussalam, 2001; Zaitoun, 2002; Wandersee, Mintez \& Novack, 1994) generally agree on the importance of scientific concepts in teaching science. However, many studies (Afra, Osta \& Zoubeir, 2007; Demirci, Cirkinoglu, 2004; Baser, 2006; Cepni \& Keles, 2006; Almassad et al., 2002; Jaber, 2004; Bawaneh, 2004) have reported a very serious problem when entry-level students arrive at school with many concepts that are inconsistent with acceptable scientific knowledge; such concepts are called alternative concepts or misconceptions. This problem has also been reported by the American Association for the Advancement of Science (AAAS, 1989) and the National Research Council, which found that students have a shallow understanding of science 
and scientific concepts. Publications from the Jordanian Ministry of Education have clearly shown that misconceptions are widely held by Jordanian students (Almassad, Abdallah, \& Mdanat, 2002); the same result has been reported by many studies (Barham, 1993, Al-Shorman, 2000, Jaber, 2004, Baz \& Bawaneh, 2008). Results from the third international study on mathematics and science, which was replicated many times (1994/1995; 1998/1999; 2002/2003), revealed commonly held misconceptions in science, especially physical concepts among eighth-grade students in many countries, including Jordan.

The problem addressed by the current study, therefore, is to survey the prevalence of scientific misconceptions, or alternative concepts, regarding electrical energy.

\section{Significance of the study}

The major purpose of the present study is to investigate the effectiveness of Conflict Maps and the V-Shape method as teaching methods in realizing scientific conceptual shifts among primary eighth-grade students. This study is important because it:

- Focuses on bringing about conceptual shifts and helping students acquire accurate scientific concepts, which is a basic objective in teaching science (Nussbaum, 1989; Rutherford, 1990, Lewis Linn, 2003).

- Compares and contrasts two teaching methods that are based on the constructivist theory and the conceptual change model.

This study seeks primarily to answer the following study question.

\section{Main study question}

Is there a statistically significant difference in the mean occurrence of scientific conceptual change (regarding electrical energy) among primary eighth-grade students that are attributable to teaching methods?

Two sub-questions derive from the main question:

7.1 Question one: Does the Conflict Map teaching method have an effect among primary eighth-grade students on the mean scientific conceptual change regarding electrical energy?

7.2 Question two: Does the V-Shape teaching method have an effect among primary eighth-grade students on the mean science conceptual change regarding electrical energy?

Although misconceptions are widely reported in various scientific fields, this study focused on concepts related to electrical energy because it forms a significant discipline of science-basically physics - and due to its practical value in daily life. Furthermore, the topic of electrical energy is studied at the primary and secondary school levels.

\section{Operational Definitions}

8.1 Misconception: A personal concept, developed through one's own experiences and self-perceptions that is inconsistent with acceptable knowledge and is characterized by constancy and change-resistance. Concepts in this study, although selected from various sources, are included in the student textbook.

8.2 Conceptual Change: A dynamic process by which alternative concepts interrelated in one's cognitive constructs are modified to fit scientifically acceptable perceptions. In this study, conceptual change is measured by student responses to the Conceptual Change Test items specifically designed for this purpose.

8.3 Conflicted Event: An instructional activity that uses devices and material from a learner's environment to introduce a concept that is contrary to what the learner believes is right and that stimulates in the learner a desire to look for underlying reasons supporting the new concept. The conflicted event disturbs the student's cognitive structures and paves the way for the targeted scientific concept to be introduced.

8.4 New Concept: A concept that is new for students, derived from the environment and in conflict with their alternative concept, which disturbs the cognitive stability of their scientifically inaccurate alternative concept by involving the conflicted event, so that students become open to receiving the accurate scientific concept.

8.5 Conflict Map: An instructional diagram designed by the teacher as an instructional tool for replacing alternative concepts (misconceptions) with scientifically acceptable concepts (Tsai, 2003). The conflict map makes salient the alternative concepts held by students regarding a given topic and then introduces a conflicted event or concept for students to work on practically or cooperatively. This concept or event creates an imbalanced state in students' cognitive constructs surrounding the alternative concept and opens the door for receiving the targeted scientific concept; thus, the first conflict between the student's alternative concept and the new concept is resolved and then the targeted scientific concept is presented. To ensure accuracy, the critical event will be presented cooperatively and practically in order to resolve the second conflict between a student's alternative concept and the targeted scientific concept.

8.6 V-Shape: A meta-cognitive instructional tool used by a student or teacher in the classroom or the lab. The V-Shape method centers on the major role of concepts in learning, retention, and making learning meaningful and identifies the 
interactivity between conceptual structures in a discipline and the methodological (operational) structures, where events and objects are found at the center of a V-Shape, where the cognitive structure starts.

\section{Methods \& Procedures}

9.1 Population Sample: The population in this study consisted of students from all male schools, in the primary eighth grade, from the Bani Kenana Provincial Directorate of Education in the Irbid Governorate in Northern Jordan. The study was conducted during the second semester of the 2008/2009 school year. Participants were chosen from a randomly selected school sample. Table (1) shows the sample schools and participant numbers.

Teaching methods, the Conflict Map and the V-Shape methods were randomly assigned to the sample. Classroom teachers with equivalent educational levels and instructional experience for the eighth grade were selected.

\section{Instruments}

\subsection{Conceptual Test}

The Conceptual Test was designed to explore conceptual change in students. Conceptual test items covered alternative concepts commonly held by students, gathered from various resources. In its final version, the test included twelve multiple-choice items, each with four choices, where only one represented the accurate response. The following is a brief description of the Conceptual Test development phases:

\section{1 .1}

Alternative concepts were collected by reviewing related literature (Broges \& Gilbert, 1999; Tsai, 2003; Baser, 2006; Cepni \& Keles, 2006; Baz \& Bawaneh, 2008). The alternative concepts selected were only those introduced by the Primary Eighth-Grade Science Textbook in Jordan during the 2008/2009 academic year.

\subsubsection{1}

Conceptual Test Validity: To test for validity, the Conceptual Test was presented to a panel of seven experts consisting of teachers, educational supervisors, and faculty members from Jordanian universities. Items ensured by the agreement of at least two raters were selected; thus, three items were removed as inconsistent with what the test was designed to measure, and three other items were modified.

\subsubsection{2}

Conceptual Test Reliability: To test for reliability, the Conceptual Test was administered to a pilot sample (N=29) of ninth-grade students who, in the previous year, studied the electrical energy unit. Students were selected from the study population. Students were informed about the test and its fields one week prior to administration. Cronbach's alpha (0.87) was found to be suitable for the purposes of this study (Audeh, 1993).

\subsubsection{3}

Difficulty and Discrimination Coefficients: Difficulty values ranged from $0.27-0.68$, and discrimination coefficients ranged from 0.27-0.86; both were found to be acceptable for the purposes of this study (Audeh, 1993).

Student responses were adjusted for the Conceptual Test by giving two scores to each item. The scores were then screened, tabulated, and input into the computer statistical process, using the Statistical Package for Social Sciences (SPSS).

\section{Instructional Content}

The first chapter, related to electricity, of the Tenth Unit from the Primary Eighth-Grade Science Textbook for the 2008/2009 academic year was studied in this study. The researchers prepared instructional booklets including lessons based on the Conflict Map and V-Shape teaching methods. Concept maps were also designed for each concept in accordance with both methods. The instructional booklets contained nine examples for each method whereas there were six Conflict Maps and six V-Shapes for each of the misconceptions.

The teachers $(\mathrm{n}=2)$ received training on the Conflict Mapping and V-Shape methods directly from the first researcher. The training occurred over two 1-hr sessions in which the objectives of both methods were identified and instructions on how to build them, as well as on how to use them in teaching science, were given; conceptual change in students was also addressed. The teachers delivered the instructional content to the groups for three weeks in four classes weekly, totaling twelve classes. This process was monitored by frequent field visits to the groups in their schools and over the phone.

\section{Study Design}

This study included two groups; the first was taught using the Conflict Map method and the other with the V-Shape method. The Conceptual Test was administered to both groups as a pretest and re-administered 31 days later as a 
posttest. This study design ensures internal validity and controls for the dispersion factor, as all subjects whose results were under analysis were pre-and post-tested.

\section{Variables}

This study included the following variables:

13.1 Independent Variable: consisted of the teaching method and had two levels:
a. Conflict Map
b. V-Shape

13.2 Dependent Variable: consisted of the conceptual change that took place in the primary eighth-grade students on the topic of electrical energy.

\section{Statistical Treatment}

Means and standard deviations were computed, and to test for mean differences, a T-test was applied with a significance level of $\alpha=0.05$.

\section{Results \& Discussion}

15.1 First: Testing the two groups' equivalence on the conceptual pretest: Table (2) shows the means and standard deviations for the student performances on the conceptual pretest in the groups under study. The comparison between the mean estimates of subject performances reveals a computational difference (0.57) in favor of the Conflict Map group. To ascertain whether this difference was substantial, a T-test was conducted, as shown in Table (2).

Table (2) demonstrates that the mean difference between the study groups was insignificant, implying that both groups were equivalent. The results show a low performance of both groups on the pretest. The mean performance of the Conflict Map group was 10.44 out of 24 (43.5\%), and the mean performance of the V-Shape group was 9.87 out of 24 $(41 \%)$.

\subsection{Second: To answer the main study question.}

15.2.1 First: Means and standard deviations in conceptual change among the Conflict Map group on the pretest and posttest revealed a mean difference in conceptual change of 4.21, in favor of conceptual change on the posttest. This mean conceptual change increased to 14.65 , representing $61 \%$. To determine whether this difference was substantial, a T-test was conducted on the data for the pretest and posttest. Table (3) shows the means and standard deviations for conceptual change among the Conflict Map group participants on the pretest and posttest, as well as the T-test results.

Results from the T-test show a statistically significant difference at $\alpha=0.05$, in favor of a mean conceptual change on the posttest, indicating that the Conflict Map method was a successful teaching method in bringing about conceptual change among this group.

15.2.2 Second: Means and standard deviations for conceptual change among the V-Shape group members on the pretest and posttest. The results revealed a difference (4.13) between mean conceptual change on the pretest and posttest, in favor of the posttest. Notably, the mean conceptual change increased to 14.00 , representing 58.5\%. To determine whether this difference was substantial, a T-test was conducted to compare the mean conceptual change on the pretest and posttest. Table (4) shows the means and standard deviations for conceptual change among the V-Shape group on the pretest and posttest, along with the T-test results.

Table (4) shows a statistically significant difference at $\alpha=0.05$, indicating that the $\mathrm{V}$-Shape method as a teaching method was perceivably successful in bringing about scientific conceptual change, regarding electricity, among primary eighth-grade students.

15.2.3 Third: To answer the main study question: "Is there a statistically significant difference in the mean occurrence of scientific conceptual change among primary eighth-grade students attributable to teaching method?" Means and standard deviations were computed for the mean conceptual change of both study groups (V-Shape and Conflict Maps). A T-test was also conducted with independent data to compare the means in light of group equivalence on the pretest. Table (5) shows results from the T-test analysis of the independent data, in order to compare the mean conceptual change for the study groups, and shows the means and standard deviations of mean conceptual change.

Table (5) reveals a difference (0.06) in mean conceptual change between the study groups in favor of the Conflict Map group; this difference was insignificant at $\alpha=0.05$. This result indicates no superiority between the two teaching methods in bringing about conceptual change and no statistically significant effect $(\alpha=0.05)$ on the mean scientific conceptual change among primary eighth-grade students attributable to teaching method.

\section{Results \& Discussion}

Results from Table (3) regarding the Conflict Map method indicate statistically significant differences in the mean conceptual change on the pretest as compared with the posttest, in favor of the posttest, attributable to the teaching method. This result demonstrates that the Conflict Map was successful in achieving conceptual change among students 
and complies with Tsai (2000), in which participating teachers confirmed the suitability of using the Conflict Map method in scientific conceptual change. Furthermore, Tsai (2003) experimentally demonstrated the superiority of the Conflict Map method in achieving change in concepts regarding simple electrical circuits; thus, it helped students to build solid and integrated mental cognitive networks. in comparison with the traditional method. Results from the present study are also consistent with the report of Baz \& Bawaneh (2008), who confirmed the positive effect of using the Conflict Map method in changing concepts regarding electricity. In comparison with the traditional method.

Results from the present study are supported by many studies aimed at verifying the effectiveness of teaching methods that rely on the conditions of conceptual change theory in making required shifts (Cosgrove, 2000; Jaber, 2004). The positive effect as represented in conceptual shifts in students exposed to the Conflict Map method can be accounted for by the following:

Conflict maps depend on invoking conflicted events that create a state of imbalance in students' cognitive structures, which in turn stimulate their search for accurate scientific concepts. In addition, they invoke critical events that confirm the accuracy of the targeted scientific concept.

Conflict maps present major concepts related to the targeted scientific concept along with the scaffolding of applied concepts that are related to the surrounding environment and practical life, thus allowing students to accurately associate scientific concepts and discover their interrelationships.

When applying conflict maps, student groups practice activities and experiments as suggested by the critical and conflicted events, which enhances their ability to learn, as individuals learn more and better when communicating with more learned and skilled peers. Vygotsky (1978) argued that a student with more knowledge and skill, a student who understands a concept earlier than a less skilled student, would be able to explain to his classmate how to understand the necessary concept.

The Conflict Map that is built principally based on Posner's conditions of conceptual change displays scientific concepts in a logical sequence.

As for the V-Shape teaching method, the results in Table (4) indicate statistically significant differences in the mean conceptual change on the pretest as compared with the posttest, in favor of the posttest. This is attributed to the teaching method. The results indicate that the V-Shape method was successful in motivating conceptual change in the students. This result is consistent with earlier studies (Al-Khraisat, 2005; Al-Zoubi, 2004; Omar, 2001; Passmore, 1998; Roth \& Roychon, 1993) that have indicated the superiority of the V-Shape method in bringing about conceptual change and meaningful learning in comparison with many teaching methods as mentioned in the previous studies.

The positive effect of the V-Shape method can be accounted for by a number of factors; teaching procedures in the V-Shape method are characterized by organization, clarity, and coherence and include an action plan for experimentation while emphasizing the role of concepts in choosing objects or events to be observed, recordings to be identified, and transformations to be performed. They also enable students to discover interrelations among concepts that are derived from observed objects and events and to explore suitable relations linking them together, as well as possible answers to the main question the group is asking.

The V-Shape method also encourages the active role of the student in the learning process, where the student can express his mind freely, so that he is able to use higher-order thinking skills, which in turn motivates students to find and refine more alternative concepts. Considered as one of the meta-cognitive strategies, the V-Shape method is thus helpful for students in understanding and apprehending concepts during learning situations.

The results shown in Table (5) indicate that neither method is superior in achieving conceptual change. Rather, both methods showed similar levels of success. This result can be accounted for by the fact that both methods spring from the same constructivist origin and that both incorporate teaching that is based on the conceptual change model, adhering to specific steps that allow the learner to modify his cognitive structure as necessary. This motivates higher-order thinking skills, thereby allowing him to realize greater integration.

It is worth noting that, to the researchers' knowledge, there exists a dearth of studies that compare and contrast two or more teaching methods based on the conceptual change model. For example, Jaber (2004) studied the effect of computer-based instruction in spurring scientific conceptual change among primary eighth-grade students. Two teaching methods were designed based on the conceptual change model, using computer software to be used with the experimental rather than the control group. Both teaching methods, based on the conceptual change model, were successful in bringing about conceptual change, whereas neither method was proven to be superior to the other.

\section{Recommendations}

In light of the results of the present study, the following recommendations are suggested:

Curriculum developers and textbook authors are advised to take into account, in their efforts to develop textbooks and instructional design, teaching strategies that are designed according to the conceptual change model, particularly 
Conflict Maps and the V-Shape method. At the same time, they should pay strict attention to practical scientific concepts.

Further studies are advised to compare the effects of conceptual change strategies on conceptual change, achievement, and retention in other subjects, such as chemistry and biology.

It is advised that training courses and workshops be held for teachers to practice using teaching strategies that are based on the conceptual change model, mainly Conflict Maps and the V-Shape method.

\section{References}

Al-Aani, R. (1996). Recent trends in the teaching of science. $\left(4^{\text {th }}\right.$ ed.). Saudi Arabia:Dar aloloum Press.

Abdelsalam, A. M. (2001). Recent trends in the teaching of science. $\left(1^{\text {st }}\right.$ ed.). Cairo: Dar Al-Fiker Al- Arabi.

American Associated for the Advancement of Science (AAAS). (1989). Literacy Goals in Science, Mathematics and Technology, Project 2061: Science for all Americans. Printed in USA, Washington. DC: Author.

American Association for The Advancement of Science, (AAAS). (1993). Benchmarks for Science Literacy. New York: Oxford University Press. [online] http://www.pitt.edu/ vtalsma/syllabi/index.htm.

Afra, Osta, \& Zoubeir, (2007). Students alternative conceptions about electricity and effect of inquiry - based teaching strategies. International Journal of Science and Mathematics Education. (7), 103-132.

Baser, M. (2006). Effect of Conceptual Change Oriented Instruction on Students' Understanding of Heat and Temperature Concepts. Journal of Maltese Education Research,4 (1), 64 -79

Borges, A.T. \& Gilbert, J.K. (1999). Mental models of electricity. International Journal of Science Education, 21(1), 95 $-117$.

Blosser, P. (1987). Science Misconceptions Research and Some Implications for the Teaching of Science to Elementary School Students. ERIC/SMEAC science Education Digest NO.1.

Barham, A. (1993). The effect of using the method of constructivism on conceptual change to the first-year secondary students to scientific concepts of acids and bases on the maintenance of this change in understanding. Doctoral dissertation, Yarmouk University, Irbid, Jordan.

Bawaneh, A. (2004). The Effect of Using Conflict Maps as an Instructional Tool in Changing Alternative Conceptions of Eight Grade Students in Science. Doctoral dissertation, The Hashemite University, Zarqa, Jordan.

Baz, T. \& Bawaneh, A. (2008). The Effect of Using Conflict Maps as an Instructional Tool in Changing Alternative Conceptions of Eight Grade Students in Science in the Hashemite Kingdom of Jordan. The Educational Journal. University of Kuwait, 87(22),149 - 189.

Cosgrove, M .(1995). A study of science - in - the -making as students generate an analogy for electricity. International Journal of Science Education, (17),295 - 310.

Demirci, N., \& Çirkinoglu, A. (2004). Determining Students' Preconceptions / Misconceptions in Electricity and Magnetism. Journal of Turkish Science Education.1 (2), 51 - 54.

Esiobu, G. \& Soyiob, K. (1995). Effects of Concept and Vee Map Under Three Learning Modes on Students' Cognitive Achievement in Ecology and Genetics. Journal of Research in Science Teaching 32(9), 971 - 995.

Epni, S., \& Keles, E.(2006). TURKISH STUDENTS' CONCEPTIONS ABOUT THE SIMPLE ELECTRIC CIRCUITS, International Journal of Science and Mathematics Education, National Science Council, Taiwan. 4: 269 291.

Hashweh, M. Z. (1986). Toward an explanation of conceptual change. European journal of science education, 8, $229-$ 249.

Jaber, R. (2004). The Effected of the Computer Aided Teaching Method on the Conceptual Change Process for Eighth Grade Science Pupils of Light Topics. MA dissertation, Yarmouk University. Irbed. Jordan.

Al-Khalil, H. (1998). Conceptual errors in chemistry at the high school students in Jordan. MA dissertation, Yarmouk University, Irbid, Jordan.

Khalili, K., Haider, A., and Yunus, M. (1996). The teaching of science in general education. United Arab Emirates: Dar Al-Qalam.

Al-Khataybeh, A. (2005). Teaching Science for All. (1 $1^{\text {st }}$ ed.). Amman, Dar Al- Maserah.

Lewis, E.L., \& Linn, M.C. (2003). Heat Energy and Temperature Concepts of Adolescents, Adults and Experts: Implications for Curricular Improvement. Journal of Research in Science Teaching, (40), 155 - 175. 
Al-Massad, M. Al-Abdallat, W. and Mdaanat, H. (2002). Manuals for teachers of science to address the errors in the learning of students in light of their findings to the questions the study of the Third International Mathematics and Science (TIMSS-R). Amman: Ministry of Education in Jordan. Management curricula and textbooks, school printing presses.

Novak, J. D. \& Gowin, D. B. (1984). Learning How to Learn. Cambridge University Press, New York, USA.

Novak, Joseph D. and Gowin,D. Bob (1995). Learning How to Learn. Translation: Safadi, Ahmad Issam El-Shafei, Mohamed Ibrahim. King Saud University. The original book published in (1984).

Novak, J. D. (2002). Meaningful Learning: The Essential Factor for Conceptual Change in Limited or Inappropriate Propositional Hierarchies Leading to Empowerment of Learners. Science Education. 86(4):548-571.

National Research Council: (NRC). (1996). Third International Mathematics and Science Study. US National Research Center, Lansing, MI.

Nussbaum, J. (1989). Classroom Conceptual Change: Philosophical Perspective. International Journal of Science Education. (11)541 - 554.

Obeidat, H. (2000). The effect of using the cooperative learning strategy and conceptual map To understand the concepts in ninth grade students in science. MA dissertation, Jordan University, Jordan, Amman.

Odeh, A. (1993). Measurement and evaluation in the learning process. ( $1^{\text {st }}$ ed.). Irbid: Dar AL Amal. Jordan.

Omar, N. (2001). The effectiveness of proposed teaching strategy Information for Processing and development of innovative thinking in science to junior high school students. Doctoral dissertation, Manofeah University, Educational Faculty, Egypt.

Passmore, G. (1998). Using Vee Diagrams to Facilitate Meaningful Learning and Misconception Remediation in Radiology Technologies Laboratory Education, 4(1).[Online] http://www.aers.org/V4N1 PASSMORE. Htm1.

Perals, F. \& Nievas, F.(1995). Teaching geometric optics: Research, results and educational implication. Research in Science and Technological Education, (13), 173 - 187.

Posner, G. J., Strike, K. A., Hewson, P. W., \& Gertzog, W. A. (1982). Accommodation of a scientific conception: Toward a theory of conceptual change. Science Education, (66), 211 - 227.

Qelada, F. (2004). Fundamentals in the Teaching of Science. Tanta, (1 ${ }^{\text {st }}$ ed.). Dar al-ma'arefa al- jamea'eh. Tanta, Egypt.

Roth, W. \& Roychon, D. (1993). Using Vee \& Concept maps in Collaborative Setting: elementary education majors construct meaning in physics Science Courses. School Science \& Mathematics, 93(5), 224 -237.

Rutherford, F.J. (1990). Science for all Americans. Oxford university press.

Al-Shorman, H. (2000). Wrong interpretations of natural phenomena to the tenth grade students in the light of knowledge content of the basic science books. MA dissertation, Yarmouk University, Irbid, Jordan.

Shehab, M. (2004). Access Safty to the knowledge, Center for Development of Teaching Science. See also [online]: http://www.t1t.net/79.htm.

Tayem, A., Shamout, O. and Zaitoun, A. (1984).Evolution of the level of scientific concepts between the 3rd preparatory grade and the 3rd secondary in some government schools in the capital Amman. Dirasat: social and educational science. (11), 89-107.

Tsai, C. C. (2000). Enhancing science instruction: the use of " Conflict Maps". International journal of science education, (22), $285-302$.

Tsai, C. C. (2003). Using a conflict map as an instructional tool to change student alternative conceptions in simple series electric - circuits. International journal of science education, 25, 307 - 327.

Vygotsky, L. S. (1978). Mind in Society: The Development of Higher Psychological Processes MA: Harvard University Press.

Wandersee,J.H., Mintzes, J.J., \& Novak, J.D. (1994). Research on Alternative Conceptions in Science in D Gablel (Ed.), NSTA, Handbook of Science Teaching and Learning: A project of the National Science Teachers Association. New York: Macmillan.

Zaitoun, K. (2002). Teaching science for understanding - construction view, (1 $1^{\text {st }}$ ed.). Alem Alfeker. Cairo. Egypt. 
AL-Zoubi, T. (2004). Using (Vee-Sheep) Maps for Physics teaching process for first year students at the University In the development of scientific thinking skills and learning and changing scientifically attitudes. Journal of Dirasat. 31 . (2), 388-408.

Table 1. Sample schools \& student numbers

\begin{tabular}{lc}
\multicolumn{1}{c}{ School Building } & Student Number \\
\hline Harima Comprehensive Boys' Secondary School & 31 \\
\hline Kharja Comprehensive Boys' Secondary School & 32 \\
\hline
\end{tabular}

Table 2. Means, standard deviations, and T-test results of independent data comparing the mean estimates of the study groups on the conceptual pretest

\begin{tabular}{|llllll|}
\hline Group & Number & M & SD & t-value & P \\
\cline { 1 - 5 } Conflict Map & 31 & 10.44 & 4.67 & 0.456 & 0.645 \\
\hline \hline V-Shape & $\mathbf{3 2}$ & $\mathbf{9 . 8 7}$ & $\mathbf{4 . 3 7}$ & \\
\hline
\end{tabular}

Table 3. Means and standard deviations of conceptual change among Conflict Group participants on the pretest and posttest, including T-test results

\begin{tabular}{|llllll|}
\hline Mean Conceptual Change & Number & M & SD & t-Value & \\
\hline Pretest & 31 & 10.44 & 4.67 & 6.01 & 0.00 \\
\hline \hline Posttest & 31 & 14.65 & 5.89 & \\
\hline
\end{tabular}

Table 4. Means and standard deviations of conceptual change among the V-Shape group on the pretest and posttest, along with T-test results

\begin{tabular}{|lccccc|}
\hline Mean Conceptual Change & Number & $M$ & $S D$ & t-Value & $\mathrm{p}$ \\
\hline Pretest & 32 & 9.87 & 4.37 & 5.31 & 0.00 \\
\hline \hline Posttest & 32 & 14.00 & 6.05 & & \\
\hline
\end{tabular}

Table 5. Results from the analysis of independent data, comparing the mean conceptual change in the study groups as well as the means and standard deviations of mean conceptual change

\begin{tabular}{|lllllr|}
\hline Group & Number & M & SD & t-Value & $p$ \\
\cline { 1 - 4 } Conflict Map & 31 & 4.20 & 3.55 & 0.069 & 0.931 \\
\hline \hline V- Shape & 32 & 4.14 & 3.76 & \\
\end{tabular}




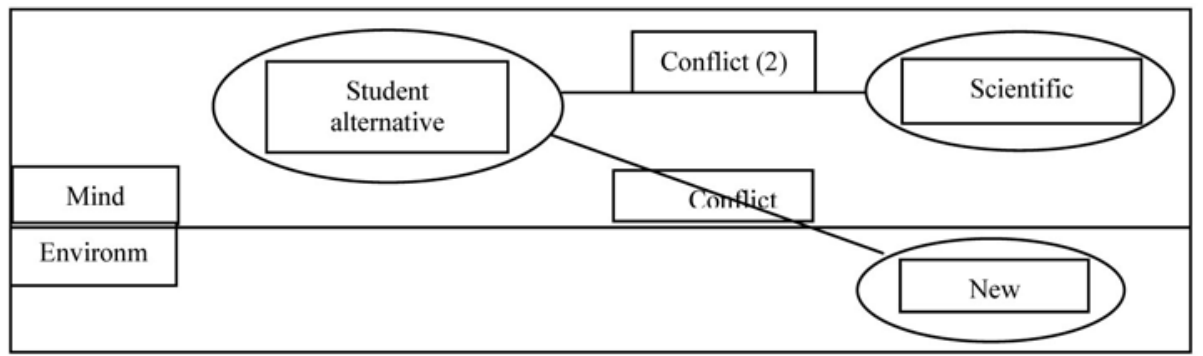

Figure 1. Hashweh model describing two conflicts in the conceptual change process (Tsai, 2000)

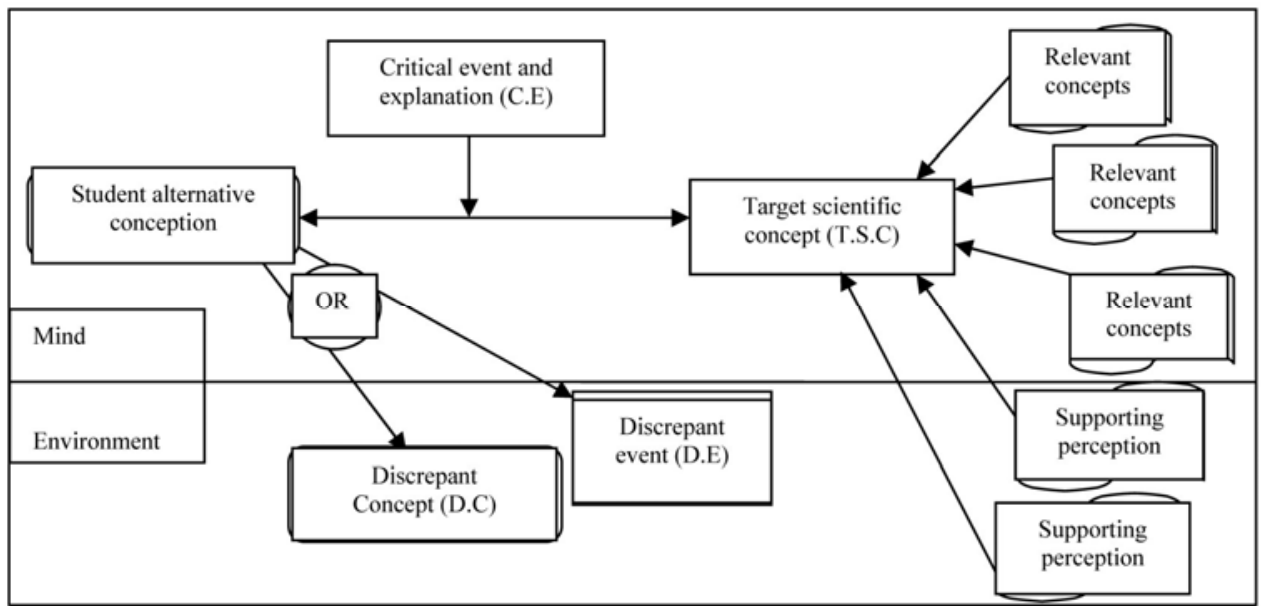

Figure 2. Conflict Map as proposed by Tsai (2000)

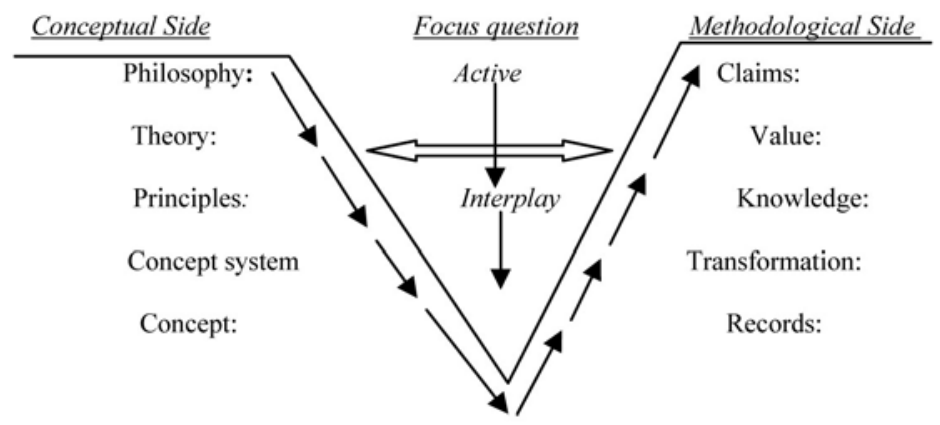

Events and / or Objects

Figure 3. V-Shape components, Ozsoy (2004). 


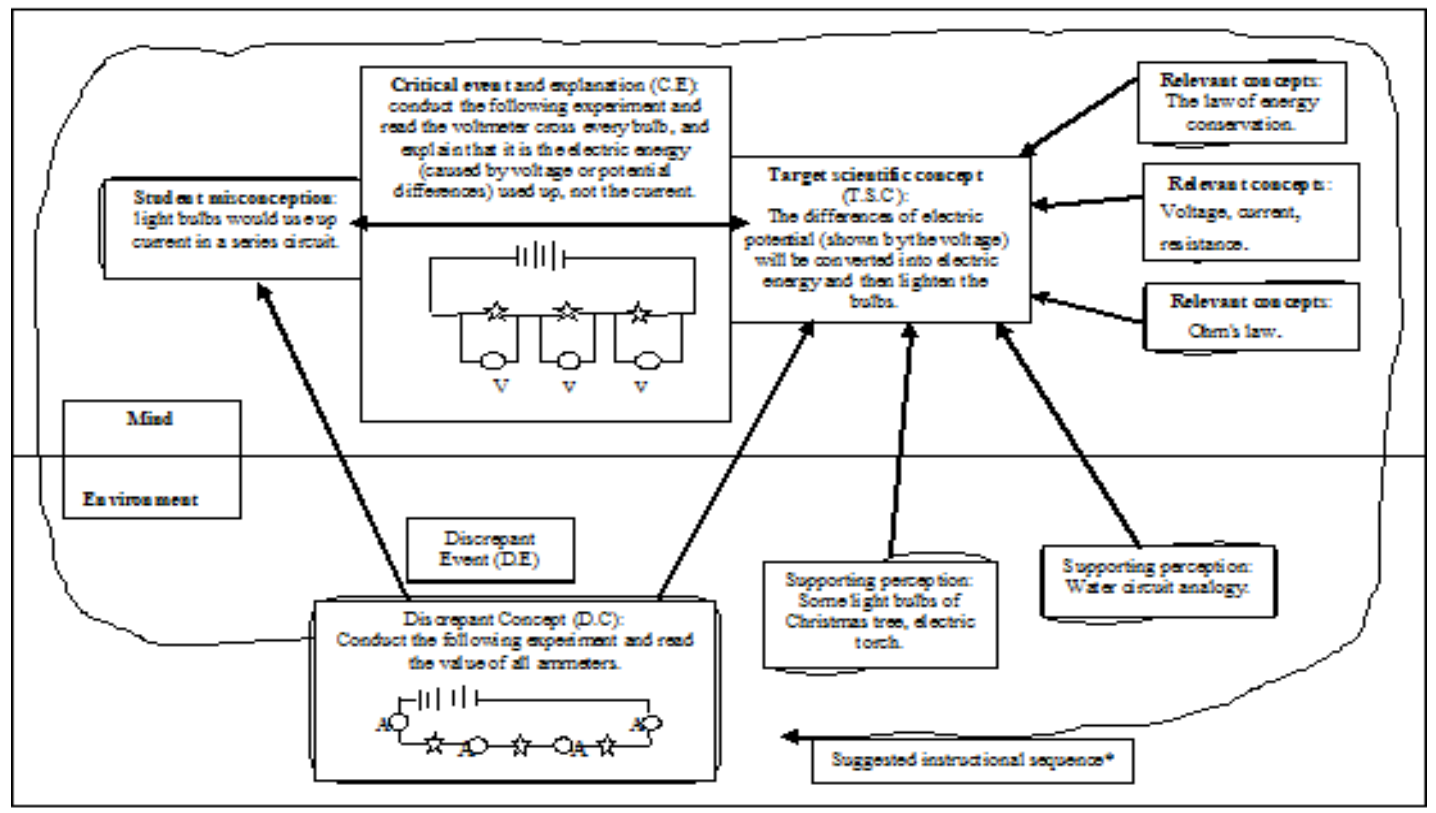

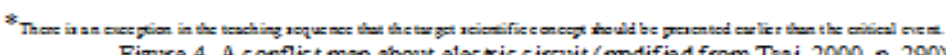
Figure 4. A conflict map about electric circuit (modified from Tsai, 2000, p. 290)

\section{V - Shape \\ Lesson: Ohm's L aw}

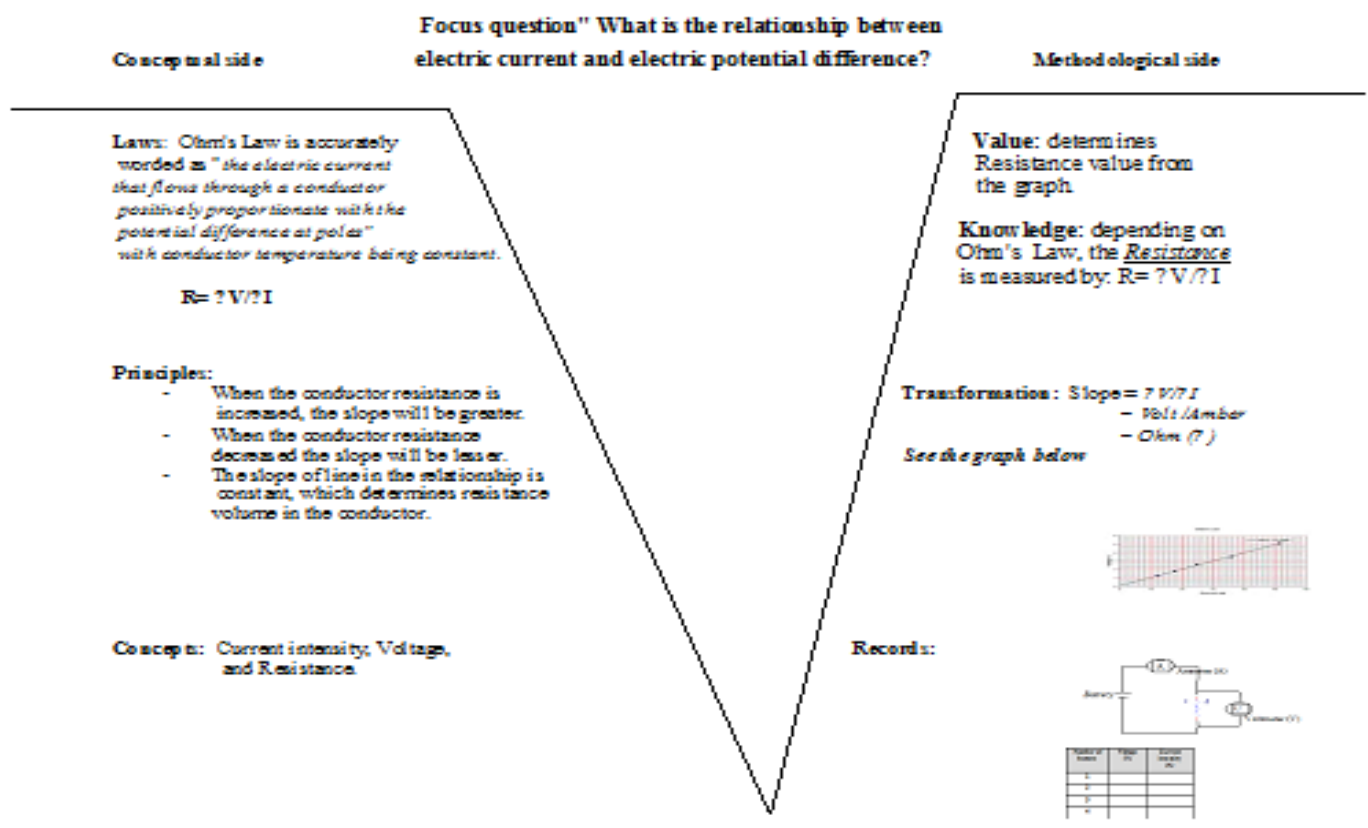

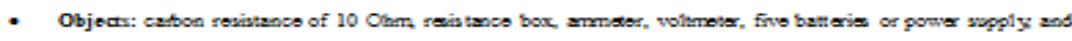
contrestor wirses.

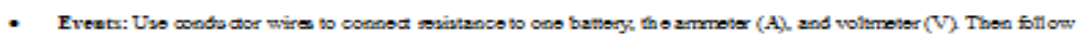
thes sepa conby one. 